\title{
Glutathione S-Transferase T1 Null Genotype is Associated with Susceptibility to Inflammatory Bowel Disease
}

\author{
Jun Qian"a,b Zhangfa Song ${ }^{c}$ Yinxiang Lvd Xuefeng Huang ${ }^{c}$ Binliang Mao \\ aDepartment of Colorectal Surgery, Xinchang People's Hospital, Xinchang, ${ }^{b}$ Department of Colorectal \\ Surgery, Xinchang Affiliated Hospital of Wenzhou Medical University, Xinchang, 'Department of \\ Colorectal Surgery, Sir Run Run Shaw Hospital, Hangzhou, 'Department of Oncology Surgery, Xinchang \\ People's Hospital, Xinchang, ${ }^{\text {eDepartment }}$ of Surgery, Affiliated Hospital of Chongqing Medical \\ University, Chongqing, China
}

\section{Key Words}

Inflammatory bowel disease • GSTT1 • Meta-analysis • Polymorphism

\begin{abstract}
Background: The published literature contains conflicting results regarding the impact of the glutathione S-transferase T1 (GSTT1) null genotype on the susceptibility to inflammatory bowel disease. Therefore, we conducted a meta-analysis of observational studies to assess the association. Methods: We searched four online databases for eligible studies. The odds ratio (OR) with $95 \% \mathrm{CI}$ was used to assess the gene-disease association. We also performed subgroup analyses by type of inflammatory bowel disease and ethnicity. Results: There were 16 individual studies from 11 publications included in the analysis. There were 3366 cases with inflammatory bowel disease and 6013 controls. The meta-analysis of all 16 studies showed the GSTT1 null genotype was associated with increased susceptibility to inflammatory bowel disease $(\mathrm{OR}=1.98,95 \% \mathrm{CI} 1.39-2.84, \mathrm{P}<0.001)$. The subgroup analysis by ethnicity further identified an association between the GSTT1 null genotype and inflammatory bowel disease in Caucasians, Asians, and Africans. The GSTT1 null genotype was associated with both ulcerative colitis (OR $=1.96, P=0.004)$ and Crohn's disease $(O R=2.01, P=0.022)$. The GSTT1 null genotype was still significantly associated with ulcerative colitis $(O R=1.63, P<0.0001)$ and Crohn's disease $(O R=1.40, P=0.023)$ after adjusting for study heterogeneity. Conclusion: The GSTT1 null genotype is significantly associated with an increased susceptibility to inflammatory bowel disease and is a risk factor for both ulcerative colitis and Crohn's disease.
\end{abstract}

(C) 2017 The Author(s)

Published by S. Karger AG, Basel

\section{Introduction}

Inflammatory bowel disease (IBD) is a chronic inflammatory disorder characterized by chronic inflammation in the gastrointestinal tract [1]. IBD affects approximately $0.1 \%$ of the population and consists of two main disease types; Crohn's disease (CD) and 
ulcerative colitis (UC). Both CD and UC can reduce quality of life [2]. Although there is still a limited understanding of the pathogenesis for CD and UC, current evidence suggests IBD is a multifactorial disease determined by several factors including genetics, environmental factors, and microbial content [3-6]. In addition, findings from familial aggregation and twin studies have shown that genetic factors are an important component involved in IBD susceptibility $[7,8]$. Recent reports have shown genetic sequence variations such as mutations in IL23R are associated with IBD [9-11].

Glutathione S-transferases (GSTs) are important enzymes involved in the detoxification of endogenous or exogenous compounds such as reactive oxygen species (ROS) [12,13]. The null genotype of the Glutathione S-transferase T1 (GSTT1) gene causes a homozygous deletion that leads to decreased activity of the GST enzyme [14]. The GSTT1 null genotype can decrease GST enzyme activity and cause oxidative stress, which may enhance the risk of IBD $[15,16]$. Several studies have investigated the association between the GSTT1 null genotype and susceptibility to IBD. However, the studies have reported conflicting results [17-22]. Duncan et al. showed the GSTT1 null genotype increased UC susceptibility but was not associated with CD [17]. Conversely, Karban et al. reported the GSTT1 null genotype increased susceptibility to CD but not UC [20]. Ernst et al. reported the GSTT1 null genotype was not associated with UC or CD [19]. Previous studies also reported conflicting findings on the association between the GSTT1 null genotype and IBD [18, 21-24]. Therefore, we conducted a meta-analysis of observational studies to evaluate the association.

\section{Materials and Methods}

\section{Literature search and eligibility of studies}

We searched the following resources to identify eligible studies: PubMed, Embase, Web of Science, Database of Chinese Scientific and the Technical Periodicals, and the Chinese Biomedical Database. The literature search was performed on September 16, 2016. There was no language limitation criteria. The literature search was performed using the following Medical Subject Headings (MeSH) or keywords: (Glutathione S-transferase T1 or Glutathione S-transferase or GSTT1 or Glutathione S-transferases or GSTs or GSTT or GST*) and (inflammatory bowel disease or Crohn's disease or ulcerative colitis). The literature search was conducted by two authors (Jun Qian and Zhangfa Song) and they reviewed the initial search results before including or excluding studies. The authors reached consensus on all possible eligible studies after reviewing the search outcomes.

The eligible studies met the following criteria: A) study of the GSTT1 null genotype impact on the susceptibility to CD or UC; B) cohort studies, cross-section studies, or case-control studies; and C) provided data for calculating the odds ratio (OR) of the association. The case-only studies and reviews were excluded from the analysis.

\section{Data extraction and quality assessment}

Two authors (Jun Qian and Zhangfa Song) independently extracted data from all included studies. The following information was collected: study ID, area, ethnicity, demographic characteristics of cases and controls, numbers of cases and controls, and distributions of GSTT1 null genotype in both cases and controls.

The study quality assessment was performed using the Newcastle-Ottawa scale (NOS) [25]. The NOS criteria state studies with 7-9 points are defined as high quality and the studies with 4-6 points are defined as middle quality. The remaining studies were considered poor quality [25]. A Hardy-Weinberg Equilibrium (HWE) is usually used to test the quality of selected controls by analysing the distributions of three genotypes of single nucleotide polymorphisms (SNP). However, this study examined the GSTT1 null genotype, which has two genotypes (Null or Non-null). Thus, the HWE was not used to test the quality of the selected controls.

Statistical methods

The pooled OR with $95 \%$ confidence interval $(95 \% \mathrm{CI})$ was used to assess the association. The heterogeneity was assessed using both the Q-statistic test and the $\mathrm{I}^{2}$ method $[26,27]$. A value for $\mathrm{I}^{2}$ greater 
than $40 \%$ indicates obvious heterogeneity and a meta-analysis using a random-effect model should be performed [28]. When $\mathrm{I}^{2}$ is less than $40 \%$ the meta-analysis should use a fixed-effect model [29]. All subgroup analyses were performed for ethnicity and type of IBD. A Galbraith plot was adopted to show the studies that result in heterogeneity [30]. The presence of publication bias was investigated by funnel plots with the Egger regression method [31]. Stata version 11.0 was used in the meta-analysis. A P-value less than 0.05 was considered statistically significant.

\section{Results}

\section{Study characteristics}

The literature search identified 157 individual studies. There were 146 studies excluded after reviewing the abstracts and full texts. Thus, 11 publications were included in the metaanalysis [17-24, 32-34]. There were five publications that assessed the association of the GSTT1 null genotype with CD and five publications for UC. Thus, we extracted 10 individual studies [17-21]. As a result, 16 individual studies from 11 publications were included in the analysis. These studies involved a total of 3366 cases and 6013 controls [17-24, 32-34]. The main characteristics of the 16 included studies in our meta-analysis are shown in Table 1. There were 11 studies that assessed the association between the GSTT1 null genotype and UC. There were 5 studies that assessed the association between the GSTT1 null genotype and CD (Table 1). In addition, 9 studies were from Caucasian countries and 5 studies were from Asian countries. There were two studies were from African countries (Table 1). The outcomes of the NOS quality assessment are shown in Table 1 . The majority of the included studies were middle quality (Table 1 ).

\section{Meta-analysis}

There was heterogeneity observed in the meta-analysis of all 16 studies on IBD $\left(\mathrm{I}^{2}\right.$ $=90.4 \%$ ). The Galbraith plot showed the studies by Mittal and Broekman were the main sources of heterogeneity (Fig. 1). The $\mathrm{I}^{2}$ value of heterogeneity decreased from $90.4 \%$ to $54.6 \%$ after excluding those two studies.

The meta-analysis of all 16 studies suggested the GSTT1 null genotype significantly increased susceptibility to IBD $(\mathrm{OR}=1.98,95 \% \mathrm{CI} 1.39-2.84, \mathrm{P}<0.001)$ (Fig. 2). The exclusion of the studies by Mittal and Broekman still showed the GSTT1 null genotype led

Table 1. Characteristics of included studies on the association between GSTT1 null genotype and IBD. (*UC, ulcerative colitis; CD, Crohn's disease)

\begin{tabular}{|c|c|c|c|c|c|c|c|c|c|c|c|}
\hline \multirow{2}{*}{ Study [ref.] } & \multirow{2}{*}{ Number } & \multirow{2}{*}{ Ethnicity } & \multirow{2}{*}{ Country } & \multirow{2}{*}{ Type* } & \multicolumn{2}{|c|}{ Case group } & \multirow[b]{2}{*}{ Non-null } & \multicolumn{3}{|c|}{ Control group } & \multirow{2}{*}{ NOS } \\
\hline & & & & & Total & Null & & Total & Null & Non-null & \\
\hline Duncan H 1995[17] & 1 & Caucasians & UK & UC & 78 & 27 & 51 & 266 & 47 & 219 & 6 \\
\hline Duncan H 1995[17] & 2 & Caucasians & UK & $\mathrm{CD}$ & 109 & 17 & 92 & 266 & 47 & 219 & 6 \\
\hline Mittal RD 2007[18] & 3 & Asians & India & UC & 85 & 77 & 8 & 164 & 26 & 138 & 5 \\
\hline Mittal RD 2007[18] & 4 & Asians & India & $\mathrm{CD}$ & 20 & 18 & 2 & 164 & 26 & 138 & 5 \\
\hline Wang W 2007[32] & 5 & Asians & China & $\mathrm{UC}$ & 99 & 64 & 35 & 140 & 66 & 74 & 4 \\
\hline Ernst A 2010[19] & 6 & Caucasians & Denmark & UC & 557 & 82 & 475 & 784 & 104 & 680 & 7 \\
\hline Ernst A 2010[19] & 7 & Caucasians & Denmark & $\mathrm{CD}$ & 383 & 66 & 317 & 784 & 104 & 680 & 7 \\
\hline Wu H $2010[33]$ & 8 & Asians & China & UC & 252 & 155 & 97 & 578 & 297 & 281 & 6 \\
\hline Ye X 2011[23] & 9 & Asians & China & UC & 270 & 175 & 95 & 623 & 294 & 329 & 5 \\
\hline Karban A 2011[20] & 10 & Caucasians & Israel & $\mathrm{UC}$ & 131 & 35 & 96 & 369 & 86 & 283 & 5 \\
\hline Karban A 2011[20] & 11 & Caucasians & Israel & $\mathrm{CD}$ & 431 & 133 & 298 & 369 & 86 & 283 & 5 \\
\hline Buyukgoze $02013[24]$ & 12 & Caucasians & Turkey & $\mathrm{UC}$ & 161 & 55 & 106 & 198 & 43 & 155 & 5 \\
\hline Broekman MM 2014[34] & 13 & Caucasians & Netherlands & UC & 552 & 73 & 479 & 972 & 203 & 769 & 7 \\
\hline Senhaji N 2015[21] & 14 & Africans & Morocco & $\mathrm{CD}$ & 77 & 26 & 51 & 100 & 17 & 83 & 5 \\
\hline Senhaji N 2015[21] & 15 & Africans & Morocco & $\mathrm{UC}$ & 33 & 14 & 19 & 100 & 17 & 83 & 5 \\
\hline Varzari A 2015[22] & 16 & Caucasians & Moldova & $\mathrm{UC}$ & 128 & 20 & 108 & 136 & 25 & 111 & 5 \\
\hline
\end{tabular}


Fig. 1. Galbraith plot to identify the main sources of heterogeneity in the meta-analysis (The number of studies were from those numbers shown in the Table 1).

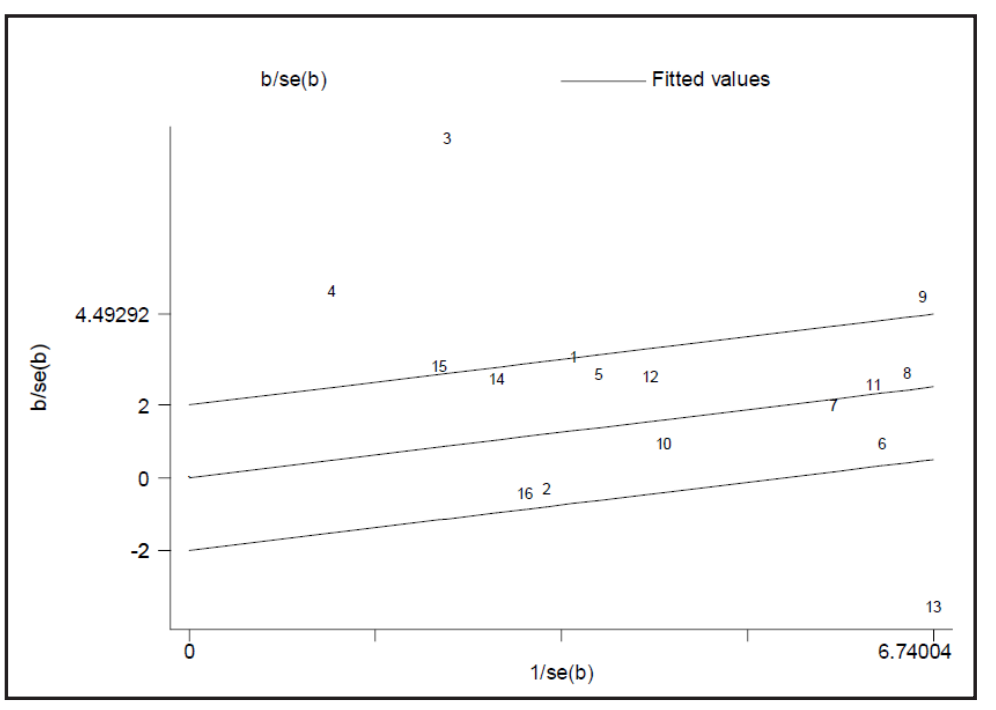

Fig. 2. Forest plot showing the association between GSTT1 null genotype and IBD (GSTT1, Glutathione S-transferase T1; 95\%CI, 95\% confidence interval; OR, odds ratio).

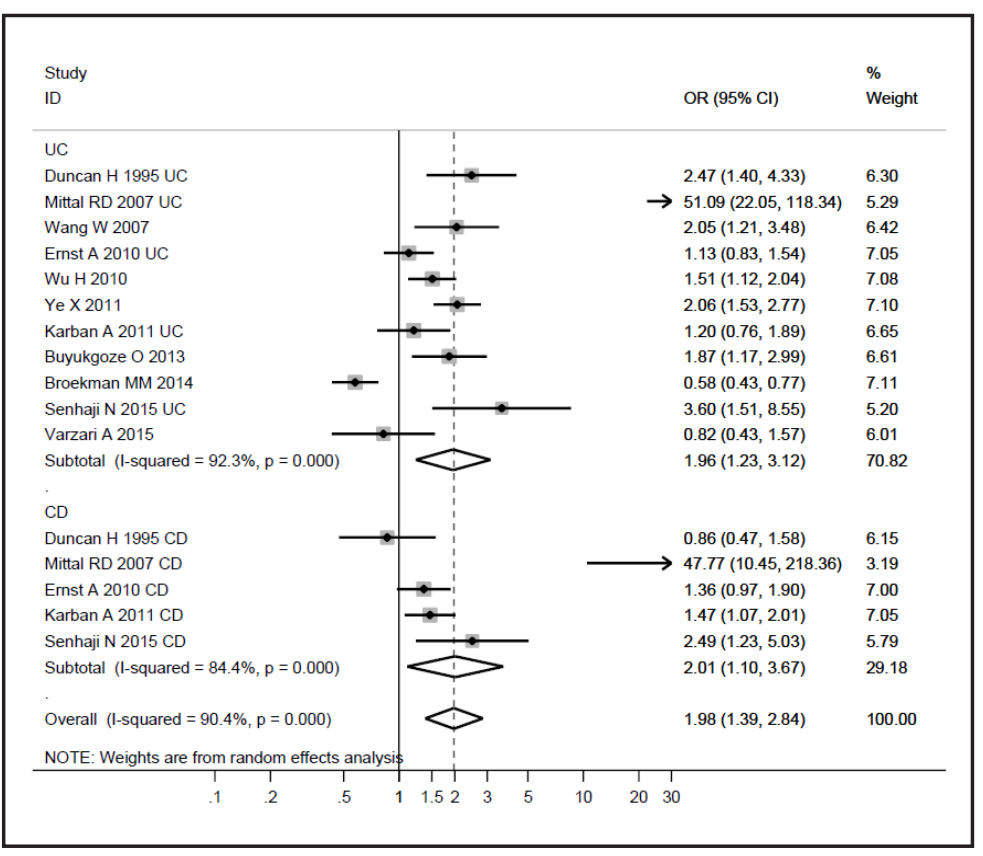

to a significantly increased susceptibility to IBD (OR $=1.55,95 \%$ CI $1.30-1.86, \mathrm{P}<0.001$; $\left.\mathrm{I}^{2}=54.6 \%\right)$. The subgroup analysis by ethnicity further identified a significant association between the GSTT1 null genotype and IBD in Caucasians (OR $=1.34,95 \% \mathrm{CI} 1.09-1.64, \mathrm{P}=$ $\left.0.005 ; \mathrm{I}^{2}=43.7 \%\right)$, Asians (OR $=1.81,95 \% \mathrm{CI} 1.46-2.25, \mathrm{P}<0.001 ; \mathrm{I}^{2}=14.0 \%$ ) and Africans $\left(\mathrm{OR}=2.88,95 \%\right.$ CI 1.67-4.98, $\left.\mathrm{P}<0.001 ; \mathrm{I}^{2}=0 \%\right)$.

There was heterogeneity observed in the meta-analysis of 11 studies on UC $\left(\mathrm{I}^{2}=92.3 \%\right)$. The GSTT1 null genotype was significantly associated with UC $(\mathrm{OR}=1.96,95 \% \mathrm{CI} 1.23-3.12$, $\mathrm{P}=0.004$ ) (Fig. 2). We adjusted the heterogeneity by excluding the studies from Mittal and Broekman. The results show the GSTT1 null genotype was still significantly associated with UC $\left(\mathrm{OR}=1.63,95 \%\right.$ CI 1.29-2.06, $\left.\mathrm{P}<0.0001 ; \mathrm{I}^{2}=60.6 \%\right)$ (Fig. 3).

There was also heterogeneity observed in the meta-analysis of 5 studies on $\mathrm{CD}\left(\mathrm{I}^{2}=\right.$ $84.4 \%)$. The GSTT1 null genotype was significantly associated with CD (OR $=2.01,95 \% \mathrm{CI}$ 1.10-3.67, $\mathrm{P}=0.022$ ) (Fig. 2). We adjusted the heterogeneity by excluding the study from Mittal and found the GSTT1 null genotype was still significantly associated with CD (OR = 1.40, 95\%CI 1.05-1.88, $\mathrm{P}=0.023 ; \mathrm{I}^{2}=41.8 \%$ ) (Fig. 3 ). 
Fig. 3. Forest plot showing the associations of GSTT1 null genotype with IBD after adjusting for part heterogeneity.

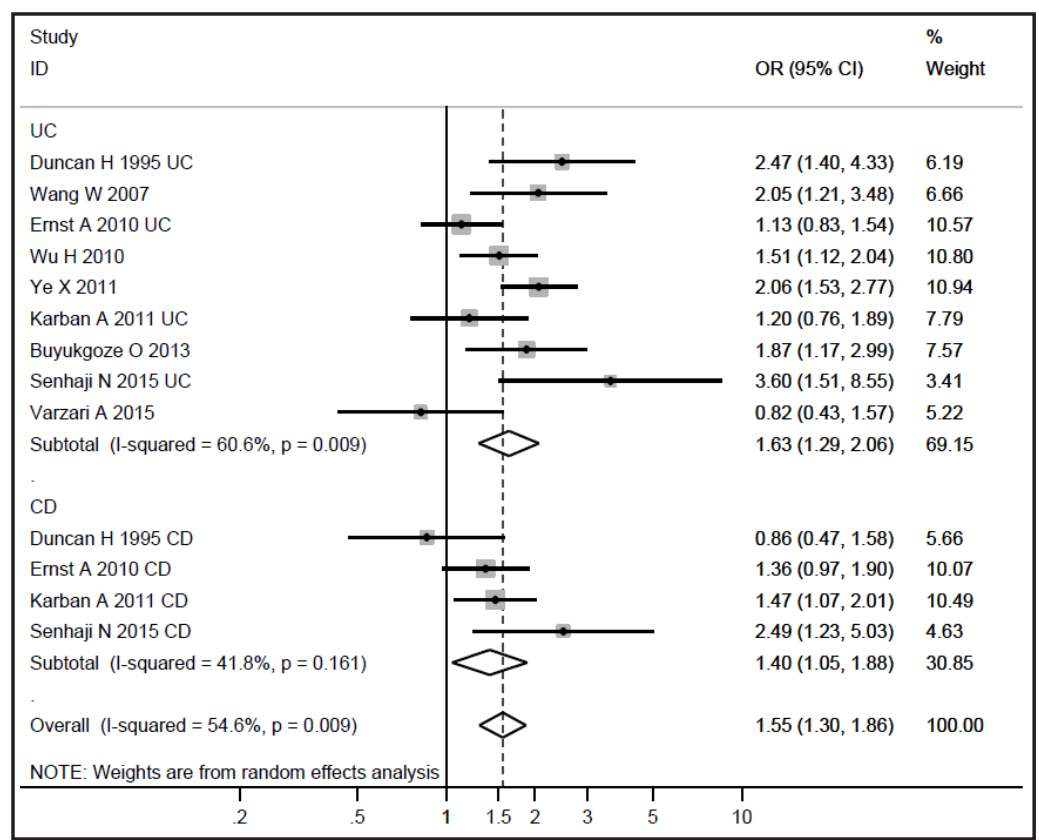

Fig. 4. Funnel plot assessing risk of publication bias in the meta-analysis.

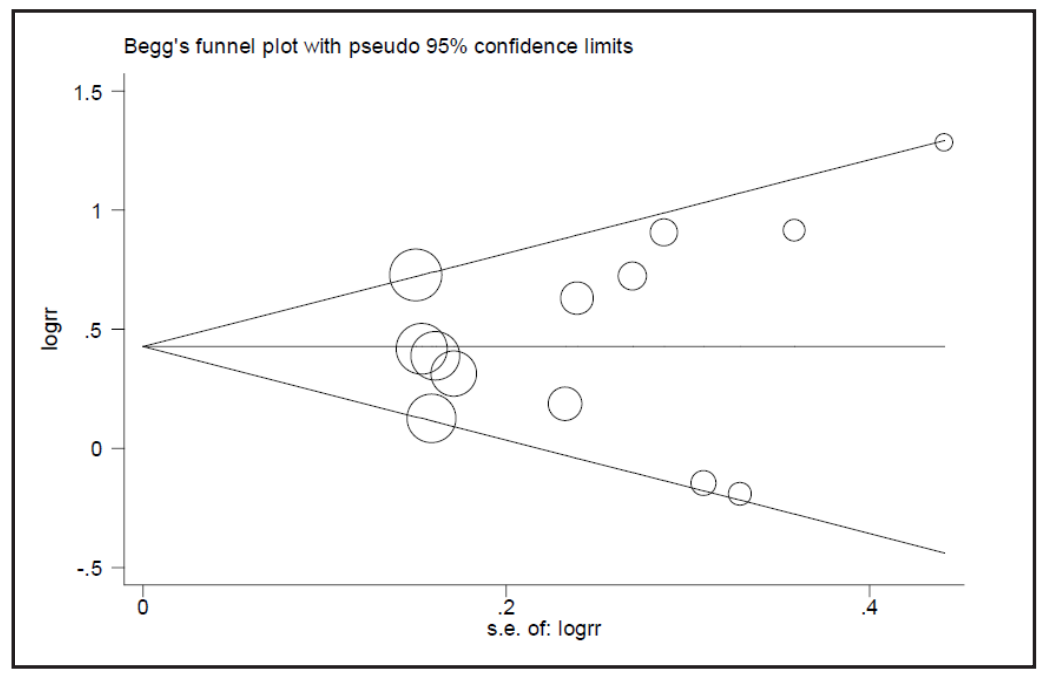

\section{Publication bias}

There was no obvious risk of publication bias shown in the funnel plot (Fig. 4). The P-value in the Egger's test was 0.55, which suggests there is no publication bias in the metaanalysis.

\section{Discussion}

This study was a meta-analysis of published observational studies and assessed the impact of the GSTT1 null genotype on IBD susceptibility. The analysis included 16 individual studies obtained from 11 publications. There were a total of 3366 cases and 6013 controls in the analysis. Our meta-analysis is the largest meta-analysis assessing the association between the GSTT1 null genotype and susceptibility to IBD. Thus, our finding will be valuable for future research. Our data indicate the GSTT1 null genotype significantly increased the susceptibility to IBD (OR = 1.98, P < 0.001; Fig. 2). Furthermore, the subgroup analysis by ethnicity identified an obvious association in Caucasians, Asians, and Africans. The GSTT1 
null genotype also significantly increased susceptibility to UC $(\mathrm{OR}=1.96, \mathrm{P}=0.004)$ and $\mathrm{CD}$ $(\mathrm{OR}=2.01, \mathrm{P}=0.022)$ (Fig. 2). The GSTT1 null genotype significantly increased susceptibility to UC or CD after adjusting the heterogeneity (Fig. 3). Therefore, the meta-analysis provided strong evidence indicating the GSTT1 null genotype is a genetic susceptibility factor for IBD, $\mathrm{UC}$, and CD.

Genetic factors are recognized as important contributors to IBD pathogenesis [35, 36]. Therefore, the identification of genetic factors associated with IBD will aid in the development of novel therapeutic targets [37]. Genome-wide association studies (GWAS) have found more than 200 genetic risk loci for IBD [38, 39]. However, the GSTT1 null genotype was not analysed in prior GWAS studies and it was unclear whether this genotype was associated with IBD. This meta-analysis pooled data from 16 individual studies and the findings suggest the GSTT1 null genotype was a genetic risk factor for both UC and CD. These results indicate the GSTT1 null genotype is possibly a novel therapeutic target.

Oxidative stress caused by increased reactive oxygen species (ROS) is an important pathogenic factor in IBD. The overproduction of ROS has been found in the inflamed mucosa of IBD patients [16]. Excessive oxidative free radicals can result in cellular stress and facilitate inflammatory reactions, which further result in the development of UC or CD [40-42]. GSTs are enzymes with important roles in the detoxification of electrophilic compounds including ROS [12]. GSTs can eliminate oxidative free radicals by glutathione and play a critical role in protecting cells against the oxidative free radicals generated by oxidative stress. The GSTT1 null genotype can lead to decreased activity of GSTs enzymes, which further increases the risk of oxidative stress and UC or CD. Therefore, the decreased GSTs activity in individuals with the GSTT1 null genotype could explain part of the mechanism underling the association between the GSTT1 null genotype and IBD. However, the mechanism underling the association is still poorly understood and additional studies are needed.

The findings in our meta-analysis provide strong epidemiological evidence for the role of the GSTT1 null genotype in UC and CD. Previous studies also have suggested that several GSTs genotypes are associated with poor clinical response to azathioprine in IBD patients. This result indicates the important roles of GSTs in the development of IBD [43,44]. However, it is still unclear whether the GSTT1 null genotype is associated with clinical response or outcomes in IBD patients and future studies are needed to explore this possibility.

There are several limitations of the meta-analysis to address. First, heterogeneity was detected in the meta-analysis of all included studies. The explanations for the heterogeneity may be the different eligibility criteria for cases or controls, or the different races of studied patients. Second, the number of published studies was not sufficient and most studies had a small sample size. There is no particular number of studies that would be considered sufficient for a meta-analysis. However, it has been conventionally considered appropriate if the number of included studies is no less than 10, especially if there is an assessment of publication bias. Additional studies are needed to further explore this association. Finally, the pooled ORs were based on unadjusted estimates and there are potentially confounding factors that were not excluded by adjustment. Gene-disease association studies usually report unadjusted ORs to assess the associations. However, studies may report adjusted ORs to provide a more appropriate estimation of the associations. In the present meta-analysis, the majority of included studies were case-control studies and reported unadjusted Ors. Therefore, we were unable to analyse the adjusted estimates.

In summary, our results show the GSTT1 null genotype is significantly associated with IBD and the GSTT1 null genotype is a risk factor for both UC and CD. Additional studies with more participants are warranted to further explore these associations.

\section{Disclosure Statement}

None. 


\section{Cellular Physiology Cell Physiol Biochem 2017;41:2545-2552 \begin{tabular}{l|l} 
and Biochemistry & DOI: 10.1159/000475978 \\
Published online: May 05, 2017 & $\begin{array}{l}\text { C } 2017 \text { The Author(s). Published by S. Karger AG, Basel } \\
\text { www.karger.com/cpb }\end{array}$
\end{tabular} \\ Qian et al.: GSTT1 and Inflammatory Bowel Disease}

\section{References}

1 Singh S, Garg SK, Pardi DS, Wang Z, Murad MH, Loftus EV, Jr.: Comparative efficacy of pharmacologic interventions in preventing relapse of Crohn's disease after surgery: a systematic review and network meta-analysis. Gastroenterology 2015;148:64-76 e62; quiz e14.

2 Alrubaiy L, Rikaby I, Dodds P, Hutchings HA, Williams JG: Systematic review of health-related quality of life measures for inflammatory bowel disease. J Crohns Colitis 2015;9:284-292.

-3 Ek WE, D'Amato M, Halfvarson J: The history of genetics in inflammatory bowel disease. Ann Gastroenterol 2014;27:294-303.

4 Dalal SR, Chang EB: The microbial basis of inflammatory bowel diseases. J Clin Invest 2014;124:41904196.

5 Raffals LE, Chang EB: Navigating the Microbial Basis of Inflammatory Bowel Diseases: Seeing the Light at the End of the Tunnel. Gut Liver 2016;10:502-508.

6 Hoehn RS, Seitz AP, Jernigan PL, Gulbins E, Edwards MJ: Ischemia/Reperfusion Injury Alters Sphingolipid Metabolism in the Gut. Cell Physiol Biochem 2016;39:1262-1270.

7 Abraham C, Cho JH: Inflammatory bowel disease. N Engl J Med 2009;361:2066-2078.

-8 Lees CW, Satsangi J: Genetics of inflammatory bowel disease: implications for disease pathogenesis and natural history. Expert Rev Gastroenterol Hepatol 2009;3:513-534.

\$ Liu JZ, van Sommeren S, Huang H, Ng SC, Alberts R, Takahashi A, Ripke S, Lee JC, Jostins L, Shah T, Abedian S, Cheon JH, Cho J, Daryani NE, Franke L, Fuyuno Y, Hart A, Juyal RC, Juyal G, Kim WH, Morris AP, Poustchi H, Newman WG, Midha V, Orchard TR, Vahedi H, Sood A, Sung JJ, Malekzadeh R, Westra HJ, Yamazaki K, Yang SK, Barrett JC, Franke A, Alizadeh BZ, Parkes M, B KT, Daly MJ, Kubo M, Anderson CA, Weersma RK: Association analyses identify 38 susceptibility loci for inflammatory bowel disease and highlight shared genetic risk across populations. Nat Genet 2015;47:979-986.

10 Grigoras CA, Ziakas PD, Jayamani E, Mylonakis E: ATG16L1 and IL23R variants and genetic susceptibility to crohn's disease: mode of inheritance based on meta-analysis of genetic association studies. Inflamm Bowel Dis 2015;21:768-776.

11 John G, Hegarty JP, Yu W, Berg A, Pastor DM, Kelly AA, Wang Y, Poritz LS, Schreiber S, Koltun WA, Lin Z: NKX2-3 variant rs11190140 is associated with IBD and alters binding of NFAT. Mol Genet Metab 2011;104:174-179.

12 Hayes JD, Flanagan JU, Jowsey IR: Glutathione transferases. Annu Rev Pharmacol Toxicol 2005;45:5188.

13 Tew KD, Townsend DM: Glutathione-s-transferases as determinants of cell survival and death. Antioxid Redox Signal 2012;17:1728-1737.

14 Strange RC, Spiteri MA, Ramachandran S, Fryer AA: Glutathione-S-transferase family of enzymes. Mutat Res 2001;482:21-26.

-15 Singhal SS, Singh SP, Singhal P, Horne D, Singhal J, Awasthi S: Antioxidant role of glutathione S-transferases: 4-Hydroxynonenal, a key molecule in stress-mediated signaling. Toxicol Appl Pharmacol 2015;289:361-370.

-16 Pereira C, Gracio D, Teixeira JP, Magro F: Oxidative Stress and DNA Damage: Implications in Inflammatory Bowel Disease. Inflamm Bowel Dis 2015;21:2403-2417.

17 Duncan H, Swan C, Green J, Jones P, Brannigan K, Alldersea J, Fryer AA, Strange RC: Susceptibility to ulcerative colitis and Crohn's disease: interactions between glutathione S-transferase GSTM1 and GSTT1 genotypes. Clin Chim Acta 1995;240:53-61.

18 Mittal RD, Manchanda PK, Bid HK, Ghoshal UC: Analysis of polymorphisms of tumor necrosis factoralpha and polymorphic xenobiotic metabolizing enzymes in inflammatory bowel disease: study from northern India. J Gastroenterol Hepatol 2007;22:920-924.

-19 Ernst A, Andersen V, Ostergaard M, Jacobsen BA, Dagiliene E, Pedersen IS, Drewes AM, Okkels H, Krarup HB: Genetic variants of glutathione S-transferases mu, theta, and pi display no susceptibility to inflammatory bowel disease in the Danish population. Scand J Gastroenterol 2010;45:1068-1075.

-20 Karban A, Krivoy N, Elkin H, Adler L, Chowers Y, Eliakim R, Efrati E: Non-Jewish Israeli IBD patients have significantly higher glutathione S-transferase GSTT1-null frequency. Dig Dis Sci 2011;56:2081-2087.

21 Senhaji N, Kassogue Y, Fahimi M, Serbati N, Badre W, Nadifi S: Genetic Polymorphisms of Multidrug Resistance Gene-1 (MDR1/ABCB1) and Glutathione S-Transferase Gene and the Risk of Inflammatory Bowel Disease among Moroccan Patients. Mediators Inflamm 2015;2015:248060. 


\section{Cellular Physiology Cell Physiol Biochem 2017;41:2545-2552 \begin{tabular}{ll|l} 
and Biochemistry & $\begin{array}{l}\text { DOI: 10.1159/000475978 } \\
\text { Published online: May 05, } 2017\end{array}$ & $\begin{array}{l}\text { C } 2017 \text { The Author(s). Published by S. Karger AG, Basel } \\
\text { www.karger.com/cpb }\end{array}$ \\
\hline
\end{tabular}

22 Varzari A, Deyneko IV, Tudor E, Turcan S: Polymorphisms of glutathione S-transferase and methylenetetrahydrofolate reductase genes in Moldavian patients with ulcerative colitis: Genotypephenotype correlation. Meta Gene 2016;7:76-82.

-23 Ye X, Jiang Y, Wang H, Chen L, Yuan S, Xia B: Genetic polymorphisms of glutathione S-transferases are associated with ulcerative colitis in central China. Cell Biochem Biophys 2011;60:323-328.

-24 Buyukgoze 0, Osmanoglu N, Arslan S, Sen A: Association of the CYP1A1*2A, GSTT1 null, GSTM1 null, mEPHX*3, and XRCC1-399 genetic polymorphisms with ulcerative colitis. Int J Colorectal Dis 2013;28:593-595.

25 Stang A: Critical evaluation of the Newcastle-Ottawa scale for the assessment of the quality of nonrandomized studies in meta-analyses. Eur J Epidemiol 2010;25:603-605.

26 Cochran WG: The combination of estimates from different experiments. Biometrics 1954;10:101-129.

27 Higgins J, Thompson SG: Quantifying heterogeneity in a meta-analysis. Stat Med 2002;21:1539-1558.

28 DerSimonian R, Laird N: Meta-analysis in clinical trials. Control Clin Trials 1986;7:177-188.

29 Mantel N, Haenszel W: Statistical aspects of the analysis of data from retrospective studies of disease. J Natl Cancer Inst 1959;22:719-748.

-30 Galbraith R: A note on graphical presentation of estimated odds ratios from several clinical trials. Stat Med 1988;7:889-894.

31 Egger M, Davey Smith G, Schneider M, Minder C: Bias in meta-analysis detected by a simple, graphical test. BMJ 1997;315:629-634.

32 Wang W, Xia X, Jiang Y, Lin L, Zhang D, Cao S: Association between genetic polymorphism of glutathione S-Transferase T1 and the susceptibility to ulcerative colitis. Shijie Huaren Xiaohua Zazhi 2007;15:533536.

33 Wu H, Zheng B, Wang J, Pei J, Jiang L, Xue Z: Relationship between genetic polymorphisms of glutathione S-transferase genes and susceptibility to ulcerative colitis in Zhejiang Han population. Shijie Huaren Xiaohua Zazhi 2010;18:2780-2784.

-34 Broekman MM, Bos C, Te Morsche RH, Hoentjen F, Roelofs HM, Peters WH, Wanten GJ, de Jong DJ: GST Theta null genotype is associated with an increased risk for ulcerative colitis: a case-control study and meta-analysis of GST Mu and GST Theta polymorphisms in inflammatory bowel disease. J Hum Genet 2014;59:575-580.

35 Loddo I, Romano C: Inflammatory Bowel Disease: Genetics, Epigenetics, and Pathogenesis. Front Immunol 2015;6:551.

-36 Uniken Venema WT, Voskuil MD, Dijkstra G, Weersma RK, Festen EA: The genetic background of Inflammatory Bowel Disease: From correlation to causality. J Pathol DOI:10.1002/path.4817.

-37 Yadav V, Varum F, Bravo R, Furrer E, Bojic D, Basit AW: Inflammatory bowel disease: exploring gut pathophysiology for novel therapeutic targets. Transl Res 2016;176:38-68.

-38 Brant SR, Okou DT, Simpson CL, Cutler DJ, Haritunians T, Bradfield JP, Chopra P, Prince J, Begum F, Kumar A, Huang C, Venkateswaran S, Datta LW, Wei Z, Thomas K, Herrinton LJ, Klapproth JA, Quiros AJ, Seminerio J, Liu Z, Alexander JS, Baldassano RN, Dudley-Brown S, et al.: Genome-wide Association Study Identifies African-Specific Susceptibility Loci in African Americans with Inflammatory Bowel Disease. Gastroenterology DOI:10.1053/j.gastro.2016.09.032.

-39 Liu TC, Stappenbeck TS: Genetics and Pathogenesis of Inflammatory Bowel Disease. Annu Rev Pathol 2016;11:127-148.

40 Gou Z, Jiang S, Zheng C, Tian Z, Lin X: Equol Inhibits LPS-Induced Oxidative Stress and Enhances the Immune Response in Chicken HD11 Macrophages. Cell Physiol Biochem 2015;36:611-621.

41 Gao D, Yang J, Wu Y, Wang Q, Lai EY, Zhu J: Targeting Dynamin 2 as a Novel Pathway to Inhibit Cardiomyocyte Apoptosis Following Oxidative Stress. Cell Physiol Biochem 2016;39:2121-2134.

42 Fan Q, Zhang Y, Liu Y, Yang J, Li D, Tang Y, Cai L, Zhao Z, Zhou P, Lu Y: Glutaredoxin Desensitizes Lens to Oxidative Stress by Connecting and Integrating Specific Signaling and Transcriptional Regulation for Antioxidant Response. Cell Physiol Biochem 2016;39:1813-1826.

43 Stocco G, Pelin M, Franca R, De Iudicibus S, Cuzzoni E, Favretto D, Martelossi S, Ventura A, Decorti G: Pharmacogenetics of azathioprine in inflammatory bowel disease: a role for glutathione-S-transferase? World J Gastroenterol 2014;20:3534-3541.

-44 Al-Judaibi B, Schwarz UI, Huda N, Dresser GK, Gregor JC, Ponich T, Chande N, Mosli M, Kim RB: Genetic Predictors of Azathioprine Toxicity and Clinical Response in Patients with Inflammatory Bowel Disease. J Popul Ther Clin Pharmacol 2016;23:e26-36. 